San Jose State University

SJSU ScholarWorks

Master's Theses

Master's Theses and Graduate Research

Summer 2013

\title{
The Relationship between Job Embeddedness and Work Engagement
}

Raymond William Ringl

San Jose State University

Follow this and additional works at: https://scholarworks.sjsu.edu/etd_theses

\section{Recommended Citation}

Ringl, Raymond William, "The Relationship between Job Embeddedness and Work Engagement" (2013).

Master's Theses. 4361.

DOI: https://doi.org/10.31979/etd.bqe4-2gdb

https://scholarworks.sjsu.edu/etd_theses/4361

This Thesis is brought to you for free and open access by the Master's Theses and Graduate Research at SJSU ScholarWorks. It has been accepted for inclusion in Master's Theses by an authorized administrator of SJSU ScholarWorks. For more information, please contact scholarworks@sjsu.edu. 
THE RELATIONSHIP BETWEEN JOB EMBEDDEDNESS AND WORK ENGAGEMENT

\author{
A Thesis \\ Presented to \\ The Faculty of the Department of Psychology \\ San José State University \\ In Partial Fulfillment \\ of the Requirements for the Degree \\ Master of Science
}

by

Raymond W. Ringl

August 2013 
(C) 2013

Raymond W. Ringl

ALL RIGHTS RESERVED 
The Designated Thesis Committee Approves the Thesis Titled

THE RELATIONSHIP BETWEEN JOB EMBEDDEDNESS AND WORK ENGAGEMENT

by

Raymond W. Ringl

APPROVED FOR THE DEPARTMENT OF PSYCHOLOGY

SAN JOSÉ STATE UNIVERSITY

August 2013

Dr. Megumi Hosoda Department of Psychology

Dr. Howard Tokunaga Department of Psychology

Timothy Brown Department of Organization and Management 


\section{ABSTRACT \\ THE RELATIONSHIP BETWEEN JOB EMBEDDEDNESS AND WORK ENGAGEMENT}

by Raymond W. Ringl

Research on job embeddedness has focused on explaining why employees choose to stay with their organizations rather than why they leave. Recently, research on job embeddedness has expanded to predict other employee behaviors such as organizational citizenship behaviors and innovation-related behaviors. To date, no research has been conducted to investigate the relationship between job embeddedness and work engagement. The purpose of this study was to add to the literature on job embeddedness by investigating relationships between the six dimensions of job embeddedness and the three dimensions of work engagement. Based on 213 participants, the study results showed that organizational embeddedness was positively related to work engagement. Furthermore, non-work aspects of a person's life-space (community fit and community sacrifice) were related to work engagement. These findings add to the utility of job embeddedness when predicting employee behaviors such as work engagement and also provide novel insight into unthought-of antecedents of work engagement. 


\section{ACKNOWLEDGEMENTS}

First of all, I would like to leave a short note to everyone who has been a part of this process and understands the struggle this has been for me.

To Luis: You have been the best thesis partner ever. I would just like to say that without having a thesis buddy like you, I would have lost my sanity nine months ago when this process first started.

To Dr. Megumi Hosoda: You have been an excellent mentor and a great source of advice and general knowledge. I am so grateful that you actually took the time to put up with me through this. I also want to thank you for giving me such valuable feedback in a candid manner; your willingness to be there for me is tremendously appreciated.

To Dr. Howard Tokunaga: Your guidance in methodology and statistics has helped me greatly and I am truly thankful that you have been there for me.

To Tim Brown: I am very happy and thankful that you were willing to be a reader of my thesis. I hope you keep me in mind if you know of any open compensation positions in the future.

Last, but certainly not least, I would like to thank all of my family and friends who have been there for me these past two years. This Master's program has been one of the greatest challenges I have taken on and without ALL of you being there as support resources, I honestly do not know where I would be.

To my Mom and Dad, I love you - thank you for all your support. 


\section{TABLE OF CONTENTS}

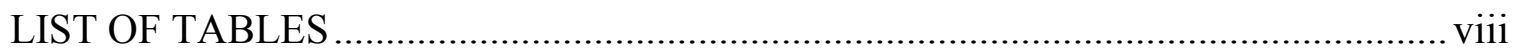

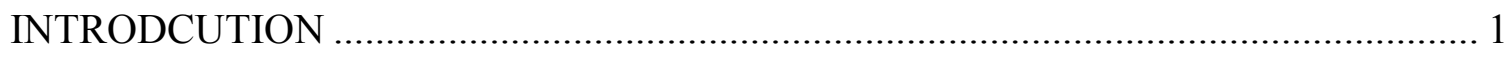

Traditional Models of Voluntary Turnover .......................................................... 3

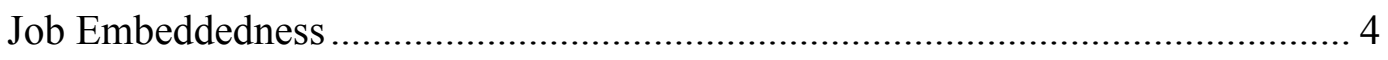

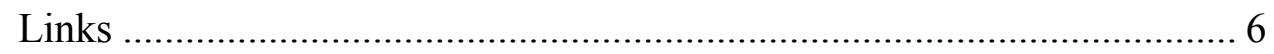

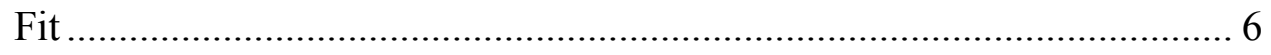

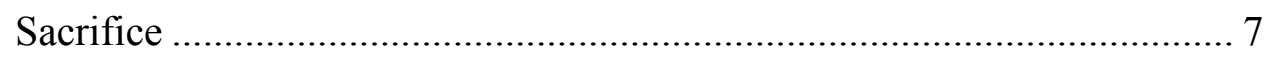

Research on Job Embeddedness ………………......................................... 8

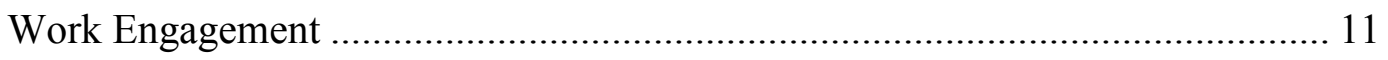

The Relationship Between Job Embeddedness and Work Engagement................ 12

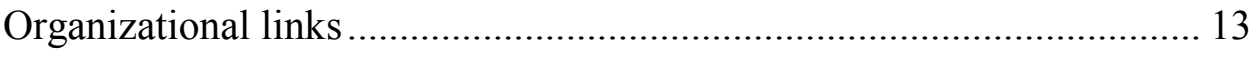

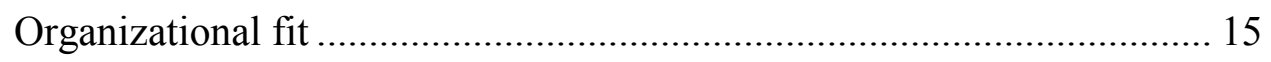

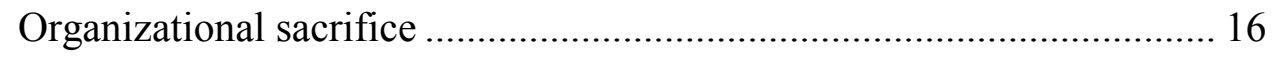

A New Direction: Community Embeddedness ..................................................... 17

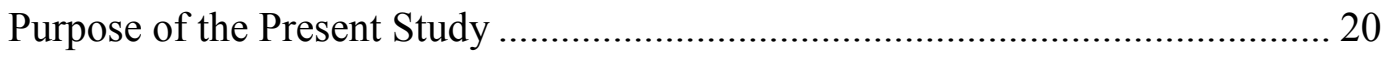

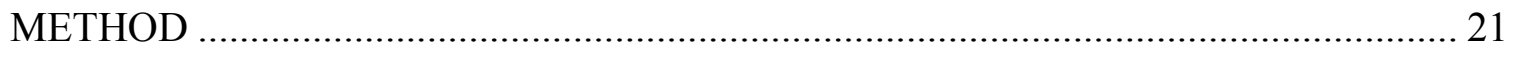

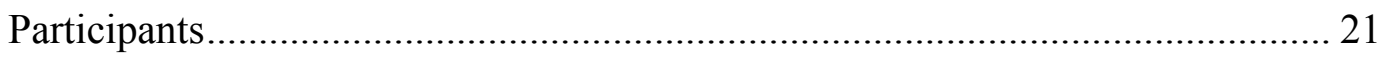

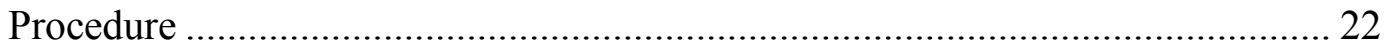

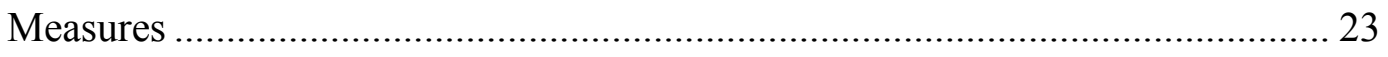

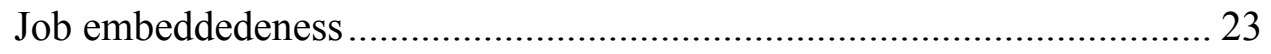

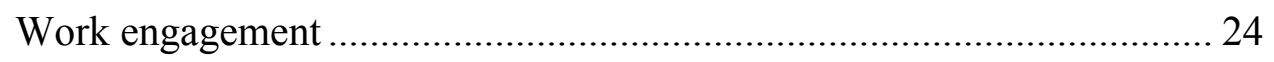




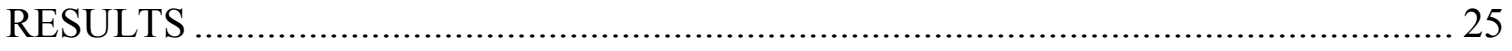

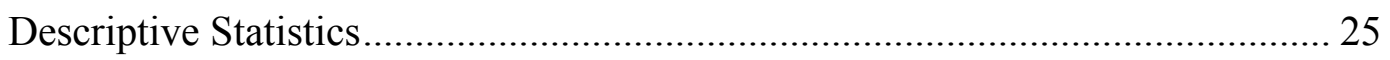

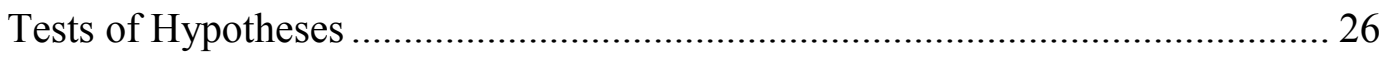

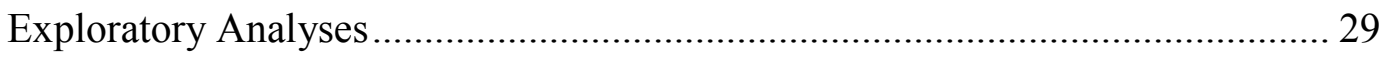

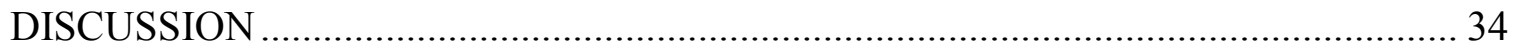

Implications of the Current Study ...................................................................... 40

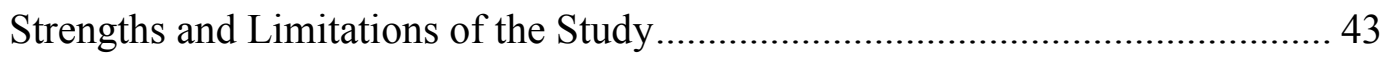

Directions for Future Research ...................................................................... 45

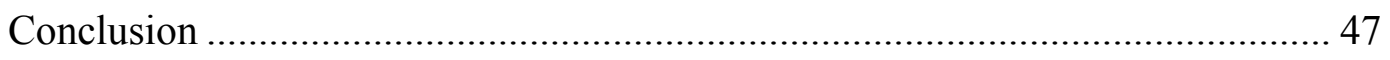

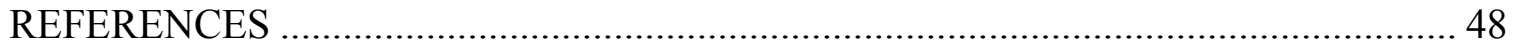

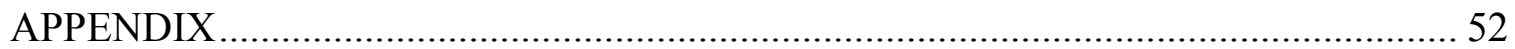

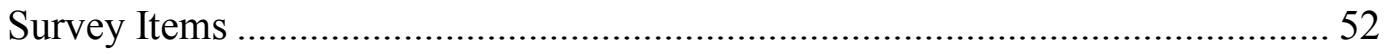




\section{LIST OF TABLES}

TABLE 1. Demographic Information of the Sample.................................................. 22

TABLE 2. Means, Standard Deviations, Pearson Correlations, and Alphas ................... 27

TABLE 3. Standard Multiple Regression Analysis - Work Engagement ...................... 30

TABLE 4. Canonical Correlations - Job Embeddedness and Work Engagement .......... 32 


\section{Introduction}

Organizations are constantly searching for new ways to keep their best employees because voluntary turnover results in a wide array of substantial costs to an organization. For every employee who leaves a company, there are recruitment costs to find a replacement, lost productivity costs due to the vacated position, and training costs needed to train a new hire. For jobs that pay under $\$ 50,000$ per year, analysts have estimated that the cost of voluntary leaving per employee is approximately $20 \%$ of that employee's annual salary (Lucas, 2012). However, when it comes to executive turnover, the cost can increase dramatically, costing up to $213 \%$ of that employee's salary (Lucas, 2012). Hence, it is not surprising that one of the top priorities for an organization's management is to answer the following questions: What causes employees to stay and what can organizations do to keep them engaged?

Traditional models of voluntary turnover use job attitudes and job alternatives as predictors of turnover (e.g., Mobley, 1977). Simply put, traditional models predict that people leave their organizations if they are unhappy with their jobs and job alternatives are available. Although job attitudes and job alternatives have been found to have consistent and negative relationships with turnover, these relationships are rather weak (Griffeth, Hom, \& Gaertner, 2000; Hom \& Griffeth, 1995). These findings indicate that work attitudes and job alternatives play only a small role in employee retention and leaving (Griffeth et al., 2000; Hom \& Griffeth, 1995).

More recently, Mitchell, Holtom, Lee, Sablynski, and Erez (2001) have developed a theory of job embeddedness to explain why people stay. Job embeddedness focuses on 
the process of retention or why people remain at their present job, suggesting that situational aspects of a person's life-space influence that person's decision to stay in a job. Research has shown that job embeddedness predicts voluntary turnover and intentions to quit above and beyond job satisfaction and organizational commitment (Mitchell et al., 2001). Furthermore, research on job embeddedness has been expanded to examine relationships with other variables such as organizational citizenship behaviors (OCB), job performance, and innovation-related behaviors (e.g., Lee, Mitchell, Sablynski, Burton, \& Holtom, 2004; Ng \& Feldman, 2010). Findings have shown that on-the-job embeddedness has a significant and positive relationship with OCB and job performance (Lee et al., 2004), along with innovation-related behaviors such as taking action to spread and implement new and innovative ideas within an organization $(\mathrm{Ng} \&$ Feldman, 2010). With positive implications of job embeddedness for organizations, it is important for companies to make efforts to increase job embeddedness in their workforces.

Just as job embeddedness research has gained increased attention in organizational psychology literature, research on work engagement has also become a zeitgeist topic amongst human resource management scholars. Work engagement has consistently been shown to be associated with positive organizational outcomes such as increased job satisfaction, lower turnover, and higher levels of individual and group performance (e.g., Bakker et al., 2005; Harter, Schmidt, \& Hayes, 2002). Due to the desirable outcomes of having engaged workforces and embedded workforces, it may be important to see if there is indeed a link between the two constructs. To this author's 
knowledge, there are no studies that have examined the relationship between job embeddedness and work engagement. Thus, the purpose of this study was to investigate the nature of the relationship between job embeddedness and work engagement. Additionally, this study examined the potential differential relationships between each dimension of job embeddedness and work engagement in order to clarify which dimension(s) may be correlated with work engagement. The forthcoming sections explain the traditional model of voluntary turnover and job embeddedness in more detail, followed by research on job embeddedness and work engagement. Finally, the hypotheses tested in the study are outlined.

\section{Traditional Models of Voluntary Turnover}

As mentioned earlier, traditional models of voluntary turnover (e.g., Hom \& Griffeth, 1995; Mobley, 1977) explain turnover in terms of two major categories: one emphasizing the desirability of movement and one emphasizing the ease of movement. The desirability of movement has come to include work attitudes like job satisfaction and organizational commitment. Ease of movement has come to include perceived job alternatives and job search behavior. Mobley (1977) developed a complex model of turnover explaining the decision process of employee turnover as a series of personal evaluations that an employee must make. Starting with an initial evaluation of one's job, an employee experiences satisfaction or dissatisfaction. Experienced dissatisfaction develops into thoughts of quitting the job, followed by an evaluation of the cost and utility of searching for alternative employment. Next, he or she develops the intention to search for job alternatives, followed by an evaluation of the perceived alternatives of 
employment. Finally, comparisons between the current job and alternative(s) are made, resulting in either an intention to quit or stay. According to this model, the direct cause of the act of quitting is the intention to quit.

Although job satisfaction and organizational commitment have been found to have consistent and negative relationships with turnover, these relationships are rather weak (Hom \& Griffeth, 1995). Hom and Griffeth (1995) and Griffeth and colleagues (2000) found that such attitudinal variables account for only $4-5 \%$ of the variance in turnover decisions. These findings indicate that job attitudes may play only a small role in employee retention and leaving. Indeed, workers may leave their jobs because of their spouse's relocation or because their family needs a bigger home, not necessarily because of job dissatisfaction. Maertz and Campion (1998) argued that, despite the consistent connection between job attitudes and job alternatives with turnover, in order to fully understand the psychology of turnover, researchers must consider factors beyond job attitudes and job alternatives. Mitchell and Campion chose to answer Maertz and Campion's call for more complete turnover explanations by focusing on why employees choose to stay, rather than why they choose to leave.

\section{Job Embeddedness}

Mitchell et al. (2001) developed the theory of job embeddedness to explain why employees stay in their organizations. Two ideas that help explain the core of job embeddedness are embedded figures and field theory (Lewin, 1951). Lewin (1951) proposed that embedded figures (a picture used in psychological tests) are images that are enveloped in their backgrounds. The foreground image is so closely enmeshed into its 
surrounding background that it becomes increasingly difficult to separate foreground from background. Similar in concept, field theory is an idea that individuals have a perceptual "life-space" where all aspects of their lives are presented and connected such that their behavior is determined by the totality of their situation (Lewin, 1951). Job embeddedness can be described as a "web" of constraining forces that cause an individual to become "stuck" in different aspects of one's life, such as a job or one's family. Consequently, job embeddedness, as its name suggests, was developed with the intention of explaining how different factors play a role in why people choose to stay in their jobs (Mitchell et al., 2001).

Unlike traditional models of turnover, job embeddedness represents a focus on the accumulated, non-affective reasons as to why employees choose to stay with their organization. Mitchell et al. (2001) claimed that their construct addresses three situational dimensions, each of which are considered both on- and off-the-job. The first of these situational dimensions is links, which is "the extent to which people have links to other people or activities" (p. 1104). The second dimension, fit, is "the extent to which their jobs and communities are similar to or fit with the other aspects in their life spaces" (p. 1104). The third factor is sacrifice, which is "the ease with which links can be broken - what they would give up if they left, especially if they had to physically move to other cities or homes" (p. 1104). Thus, with the three factors encompassing what makes employees embedded both on- and off-the-job, there exists a $3 \times 2$ matrix of "forces" that cause employees to become embedded within their jobs. 
Links. Organizational links are characterized as formal or informal connections between a person and institutions or other people that are formed as a result of working for an organization (Mitchell et al., 2001). These links can include social relationships, such as coworkers, supervisors, and the number of teams or work committees of which one is a part. In this theory, the more links an employee has to his or her organization, the more likely he or she will be reluctant to sever ties from the organization.

Community links are the social ties one has with those who live in one's geographical region. For example, a person may have a group of friends he or she gets together with on a weekly basis, or may have numerous family members within a short distance of his or her home. The theory states that the more links one has in his or her community, the harder it will be to give up those links and leave the community.

Fit. Organizational fit is defined as “an employee's perceived compatibility or comfort with an organization" (Mitchell et al., 2001, p. 1104). According to job embeddedness theory, the greater the perceived congruence between an employee's knowledge, skills, and abilities (KSAs) and those required by one's job, the more he or she perceives organizational fit. Also considered in organizational fit is a degree of perceived congruence between one's own values and goals and those of the organization. The greater the congruence, the more one perceives fit with an organization. An employee who experiences a high degree of fit will be more attached to that organization, making it harder to sever ties from the organization.

Community fit is described as the perceived fit one has with the community in which he or she lives. This includes a perception of fit between an employee and his or 
her community's culture, how well he or she enjoys the climate within the community, and the available amenities that the community's geographical location has to offer (Mitchell et al., 2001). Job embeddedness theory posits that the greater the congruence between one's wants and needs of his or her community and what the community actually has to offer, the more likely one will want to preserve this congruence because it is meaningful to the individual.

Sacrifice. Organizational sacrifice is considered "the perceived cost of material or psychological benefits that may be forfeited by leaving a job" (Mitchell et al., 2001, p. 1105). An employee who leaves an organization may have to give up cherished work relationships, position in a job hierarchy, presence on work teams and committees, and benefits that are offered at the employee's organization. This theory says that an employee who is considering quitting but does not want to sacrifice valued job-related perks and social relationships would be less likely to terminate employment.

Community sacrifice is described as the perceived sacrifice one must make in order to give up one's community. If an employee were to leave one's community to take a job in a different geographical location, one may need to sell his or her house, leave a pleasant community, lose valued social relationships, or give up a convenient work commute. If an employee values the aspects of the community one lives in, one will be more reluctant to give up his or her job. According to job embeddedness theory, community sacrifice plays an important role in an employee's decision to leave or stay.

In sum, these facets of an individual's on- and off-the-job life form a contextual "web" that causes a person to become embedded in his or her organization and 
community. The aspects of links, fit, and sacrifice work together to create an overarching collection of retaining forces that influence an employee's decision to stay in his or her job.

\section{Research on Job Embeddedness}

Since the theory of job embeddedness was introduced, research has mainly examined the predictive validity of job embeddedness on voluntary turnover. For example, Mitchell and colleagues (2001) found empirical support for the utility of job embeddedness as an antecedent of voluntary turnover. Using data from two organizations, they examined employee intention to leave and actual turnover by measuring job satisfaction, organizational commitment, job search, perceived alternatives of employment, and lastly, job embeddedness. They found that job embeddedness was negatively related with intentions to leave and subsequent voluntary turnover.

Additionally, they found that each dimension of both on- and off-the-job embeddedness (i.e., links, fit, and sacrifice) was significantly related to turnover outcomes in at least one of their two study samples. Of note in their study is that job embeddedness was found to explain turnover above and beyond job satisfaction, organizational commitment, job alternatives, and job search. From their findings, Mitchell et al. (2001) contended that organizations should analyze and understand their employees' lives both on- and off-thejob if they want to retain them in the long term.

More recently, research on job embeddedness has been expanded to include variables other than voluntary turnover. For example, Lee and colleagues (2004) examined additional organizational outcomes of embedded workforces. They 
hypothesized that employees who are embedded on-the-job would be more likely to display higher in-role (i.e., job performance) and extra-role (i.e., organizational citizenship behavior) performance because these individuals are socially enmeshed into the organization, and therefore are likely to cooperate with and assist coworkers on assignments. They also hypothesized that those embedded off-the-job are less likely to be absent and subsequently quit because their jobs are the financial backbone that support their community lifestyle. Being absent or quitting may jeopardize an employee's ability to reside within the community he or she desires. In line with their hypotheses, they found that organizational embeddedness was significantly associated with higher levels of OCB and job performance. They also found that, after controlling for job satisfaction and organizational commitment, off-the-job embeddedness (but not on-the-job embeddedness) predicted absences and subsequent turnover. Their results indicated that different types of job embeddedness increased attendance, retention, job performance, and OCB.

Similarly, in a cross-cultural effort to extend job embeddedness theory, Cho and Ryu (2009) sought to replicate Lee and colleagues' study (2004) by examining the relationship of on-the-job embeddedness with OCB and job performance among South Korean employees. In addition to hypothesizing that organizational links, organizational fit, and organizational sacrifice would be related to $\mathrm{OCB}$, they also argued that $\mathrm{OCB}$ should mediate the relationship between on-the-job embeddedness and job performance. They believed that on-the-job embeddedness would lead to increased OCB, which in turn, would lead to higher quality job performance. In partial support of their hypotheses, 
they found that organizational links, fit, and sacrifice were all positively related to OCB. They also found that OCB mediated the relationship between on-the-job embeddedness and job performance.

$\mathrm{Ng}$ and Feldman (2010) further expanded on job embeddedness research by examining the impact of job embeddedness on innovation-related behaviors. They examined three types of innovation-related behaviors: (a) generating new ideas, (b) sharing ideas with colleagues, supervisors, and spreading innovation throughout the organization, and (c) working to implement those innovations themselves or helping others do so. Ng and Feldman hypothesized that job embeddedness would be positively related to innovation-related behaviors because embeddedness "fosters a strong sense of responsibility to contribute fully to long-time employers" (p. 1070). In support of their hypothesis, they found that job embeddedness was positively related to higher levels of all three types of innovation related-behaviors. They concluded that embedded employees were motivated to move forward the organization's best interests and that displaying more innovation-related behaviors was a vehicle toward doing so.

The above literature shows that job embeddedness is related to organizational outcomes such as voluntary turnover, OCBs, job performance, volitional absences, and innovation-related behaviors. With the increasing attention given to job embeddedness in the literature, it is somewhat surprising that researchers have not yet attempted to examine its relationship with work engagement. Sections forthcoming will introduce the concept of work engagement and discuss why job embeddedness is thought to be related to work engagement. 


\section{Work Engagement}

Work engagement has been characterized as "a positive fulfilling, work-related state of mind that is characterized by vigor, dedication, and absorption" (Schaufeli, Salanova, Gonzalez-Roma, \& Bakker, 2002, p. 74). Engaged employees are not only more likely to invest physical effort in their work, but because they experience increased meaningfulness in their work, they are also more likely to be cognitively and emotionally attached to their work (Kahn, 1990).

Schaufeli et al. (2002) characterized vigor as having "high levels of energy and mental resilience while working, the willingness to invest effort in one's work, and persistence even in the face of difficulties" (p. 74). This positive state of mind helps employees more readily take on the daily obstacles and challenges of work and invest extra effort to get work done. They characterized dedication as having a "sense of significance, enthusiasm, inspiration, pride, and challenge" in one's work duties (p. 74). Those who have high levels of dedication are not only highly involved in their job duties, but also have a positive affect toward the work they do. Thus, dedication involves a sense of commitment and positive feelings towards one's work. Finally, Schaufeli et al. (2002) characterized absorption as "being fully concentrated and deeply engrossed in one's work, whereby time passes quickly and one has difficulties with detaching oneself from work" (p. 74). Absorption in one's work allows one to fully focus his or her personal resources on the task at hand - filtering out what is not relevant to the work, and concentrating on the necessary information to complete the work. 
Work engagement has become a popular topic of research in the area of organizational behavior as it is has been found to be related to several valued organizational outcomes. For example, Harter, Schmidt, and Hayes (2002) conducted a meta-analysis on work engagement by examining 7,939 business units in 36 companies and found that work engagement was significantly and positively related to key outcomes such as customer satisfaction, worker productivity, profit, employee retention, and employee safety. Empirical research on work engagement has suggested that engaged workforces have more positive job attitudes (e.g., Harter et al., 2002), lower turnover (e.g., Bakker, Demerouti, \& Schaufeli 2005), and higher levels of employee performance (e.g., Harter et al., 2002). Accordingly, investigating additional factors that predict work engagement is central to understanding how to make workforces more effective.

\section{The Relationship Between Job Embeddedness and Work Engagement}

There are important reasons for examining the relationship between job embeddedness and work engagement. First, although embeddedness infers that employees are enmeshed in a constraining web that keeps them in their jobs (Mitchell et al., 2001), it is not known if embedded individuals are actually engaged in their work. Understanding the dynamic between the two constructs and identifying relationships among their subdimensions may provide organizational psychologists additional clues as to how employees become engaged on-the-job and what may be related to lower employee engagement.

Additionally, examining how the components of on-the-job and off-the-job embeddedness might be differentially related to work engagement may provide unique 
insight to the utility of job embeddedness. Existing literature leads one to believe that there is indeed a relationship between job embeddedness and work engagement. The theoretical underpinning for examining the different dimensions of job embeddedness in relation to work engagement is discussed below in detail.

Organizational links. Because organizational links are characterized as formal or informal social ties to people in an organization, they can be viewed as a type of job resource that fosters work engagement. According to the job demands-resources model (JD-R model) (Demerouti, Bakker, Nachreiner, \& Schaufeli, 2001), there are two types of work characteristics inherent in any type of job: job resources and job demands. Job resources are characterized as "aspects of a job that are functional in achieving work goals, may reduce job demands and the associated physiological and psychological costs, and stimulate personal growth, learning and development" (Mauno, Kinnunen, Makikangas, \& Feldt, 2010, p. 112). Examples of job resources include social support, participation in decision-making, job control, and opportunity for advancement (Demerouti et al., 2001). Job demands refer to "physical, social, or organizational aspects of the job that require sustained physical or mental effort and are therefore associated with certain physiological and psychological costs" (Demerouti et al., 2001, p. 501). Examples of job demands include workload, time pressures, and emotional demands.

Of the job resources available to employees, Bakker, Demerouti, and Euwema (2005) argued that social support networks are one of the most well known types of work characteristics that are functional in achieving work goals. Social support networks have 
been shown to be instrumental in buffering the negative effects of job demands on work strain experienced by workers (Bakker et al., 2005). They are also critical in reducing the effects of work overload on employees, helping them complete challenging work tasks on time. As an important aspect of an employee's social support network, a supportive and helpful manager may be viewed as a job resource because managers can be key resources for information, advice, and support to complete challenging tasks, providing emotional support, as well as serving as an organizational role model to the employee.

As an employee develops an increasing number of formal and informal connections to other people within the organization, this social support network is viewed as a job resource that can boost motivational processes at work. Consequently, a larger social support network (i.e., increased links) may be a predictor of work engagement. In general, one would expect that as the number of organizational links increases, these links serve as job resources, which are likely to promote work engagement.

Hypothesis 1: Perceived organizational links will be positively related to work engagement. 
Organizational fit. According to job embeddedness theory, a perception of fit between one's KSAs and the requirements of the job results in organizational fit (Mitchell et al., 2001). Also important in organizational fit is a level of perceived match between an employee's personal values, career goals, and aspirations and the organization's culture and direction. Thus, according to Mitchell et al. (2001), employees who perceive congruence between their own values and goals and those of their organizations are said to perceive high organizational fit. One plausible consequence of organizational fit may be that, when employees perform work that is highly tied to their KSAs and personal values, they tend to experience positive feelings that make them feel useful and thus realize that their efforts are worthwhile.

Research on value congruence (e.g., Chatman, 1989; Kristof, 1996) has argued that when an organization expects a set of behaviors from employees that are closely tied (congruent) with how employees prefer to see themselves (their preferred self-image), employees are likely to fully invest their physical, psychological, and emotional effort into the set of duties that make up their jobs, thus, becoming more engaged on the job. In a similar vein, according to Maslach and Leiter (1997), fit between the characteristics of an individual and the environment of his or her job (i.e., person-job congruity), is related to engagement with one's job. Their work engagement model suggests that the greater the congruity between the job and the person, the greater the likelihood of work engagement. Following these similar theories, one would expect that as the perception of fit between one's KSAs and those required by his or her job, as well as fit between one's 
values, goals, and aspirations with those of the organization increases, work engagement is likely to increase. Thus, the following hypothesis is put forth:

Hypothesis 2: A perception of organizational fit will be positively related to work engagement.

Organizational sacrifice. An employee who has many social relationships with those at work, holds seniority over other coworkers, values particular benefits one's job, or has advancement opportunities may experience a high level of perceived sacrifice if he or she were to leave the job (Mitchell et al., 2001). According to the JD-R model (Bakker \& Demerouti, 2007), these aspects of a job may be viewed as job resources because they are aspects of a job that are valued and motivating for employees. As such, employees may be reluctant to give up their colleagues, advancement opportunities, perks, and benefits.

Conservation of resources theory (COR theory) (Hobfoll, 1989) posits that individuals seek to obtain, retain, and protect resources that they personally value. In this case, employees may be motivated to protect and maintain social resources such as familiar and developed relationships with colleagues, personal resources such as valued benefits, and perks one may have attained such as seniority and status within a job. Hobfoll and Shirom (2001) maintain that in order to prevent the loss of these valued resources, individuals must invest personal resources to protect the loss of tangible external resources. In this case, one would argue that individuals invest their psychological, physical, and emotional energies to protect valued job resources; that is, they increase their level of work engagement into their job to preserve current job 
resources. Further, employees who highly value these resources are likely to perceive a high level of sacrifice needed to give up these resources and may potentially invest higher levels of physical and psychological energies to attain additional job resources they value (Hobfoll \& Shirom, 2001). Following this argument, it is conceivable that employees who perceive a high level of organizational sacrifice would become engaged in their jobs. Thus, the following hypothesis is put forth:

Hypothesis 3: A perception of organizational sacrifice will be positively related to work engagement.

\section{A New Direction: Off-The-Job Embeddedness}

As it is reasonable to expect that antecedents of work engagement should, in fact, be aspects of a job that reside within the work domain, the vast majority of researchers (e.g., Harter et al., 2002; Maslach \& Leiter, 1997) who have investigated antecedents of work engagement have focused on at-work characteristics of an employee's job (e.g., autonomy, supervisor support). However, it may be worthwhile to expand the predictors of work engagement to non-job-related factors of an employee's life. To the author's knowledge, there has been no research that addresses the relationship between community embeddedness and work engagement. However, there are a few studies that have examined off-the-job factors in regard to work engagement.

Research in health psychology and work stress suggests that aspects of one's offthe-job life may increase work engagement (Kinnunen et al., 2011; Sonnentag et al., 2008). For instance, Sonnentag et al., (2008) found that psychological detachment from work during off-the-job hours was an important factor in predicting engagement for 
employees in the long-term. Participants in their study who detached from work and became engaged in their off-work lives during off-work hours were more able to recover psychological energies expended during work hours. Similarly, Kinnunen et al. (2011) found that psychological detachment from work mediated the effects of job demands on fatigue. Their mediation model explained that increased job demands were related to an inability to psychologically detach from work, which in turn, led to job-related fatigue. Therefore, to remain engaged in the long term, psychological detachment from work is necessary to reduce the possibility of fatigue and increase the likelihood of work engagement.

Additionally, Kinnunen et al. (2011) investigated aspects of an individual's offthe-job life that may be useful in recovering from the stress produced by work demands. They argued that those who regularly engaged mastery experiences should more readily recover from work demands. They defined mastery experiences as off-the-job activities that provide challenges and opportunities to learn new skills (e.g., taking a language class or learning a new sport). Although these mastery experiences may initially pose a demand to an individual because of the psychological energy they require, Sonnentag and Fritz (2007) argued that these experiences should actually enhance recovery from work demands because they help foster the formation of new internal job resources such as new knowledge, skills, competencies, self-efficacy, and positive mood. As a result, these newly formed job resources, according to the JD-R model, should increase the likelihood of work engagement (Bakker \& Demerouti, 2007). In support of their hypothesis, they found that off-the-job mastery experiences partially mediated the relationship between 
job resources and engagement, suggesting that off-work aspects of an individual's life may be an important factor toward promoting work engagement (Kinnunen et al., 2011). Another argument for the idea that off-work facets of employees' lives are important for work engagement came from Lee et al. (2004) who argued that those who are embedded in their communities tend to view them as resources worth keeping. As a result, they are motivated to keep their jobs in order to remain in their communities. As stated earlier, conservation of resources theory (Hobfoll, 1989) posits that people are motivated to protect resources they personally value. Following Hobfoll and Shirom (2001), employees who have many off-the-job links, perceive fit in their community, and perceive a great deal of sacrifice if they left their communities, should be motivated to invest personal resources (e.g., psychological, emotional, and physical) in order to prevent the loss of these valued off-the-job resources.

Because good job performance is directly tied to maintaining employment (i.e., not being fired), and that being fired may result in the inability for one to preserve the community resources he or she values, an individual who is embedded in his or her community should be motivated to expend psychological, emotional, physical resources necessary to perform well and maintain one's job. The expenditure of these personal resources should be related to increased engagement on the job. However, given that there is limited research on this particular reasoning, no formal hypotheses are presented; instead more conservative research questions are put forth.

RQIa: Is a perception of community links related to work engagement? RQ1b: Is a perception of community fit related to work engagement? 
RQ1c: Is a perception of community sacrifice related to work engagement?

\section{Purpose of the Present Study}

The purpose of this study is to build upon and add to the value of the current framework of job embeddedness theory by examining whether or not this construct is related to work engagement. Additionally, this research will disaggregate the job embeddedness construct into its components (on- and off-the-job; links, fit, and sacrifice), allowing for a more in-depth understanding of how the dimensions of job embeddedness may be differentially useful in the prediction of work engagement. This research will also add original insight to the literature regarding the relationship between off-job factors that may be related to the prediction of work engagement. 


\section{Method}

\section{Participants}

The sample for this study consisted of 213 individuals who completed a survey online or in class. Participants were recruited from San José State University's

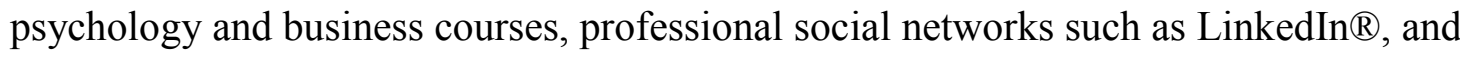
through the researcher's professional contacts.

Table 1 presents the demographic information of the sample. Of the 213 participants, $42.3 \%(n=90)$ were male and 57.3\% $(n=122)$ were female. Participants' age ranged from 19 to 65 with $(M=27.8, S D=8.31)$. The ethnicity of the sample primarily consisted of people of White/Caucasian (45.1\%) and Asian/Asian American (34.7\%) decent. Finally, participants' salary was very positively skewed towards the

lower end of the salary scale, with the majority of the sample $(69.0 \%)$ making less than $\$ 40,000$ per year. 
Table 1

Demographic Information of the Sample $(N=213)$

\begin{tabular}{|c|c|c|c|c|c|}
\hline Demographic & & Mean & $S D$ & $\mathrm{n}$ & $\%$ \\
\hline Age & & 27.8 & 8.31 & & \\
\hline \multicolumn{6}{|l|}{ Sex } \\
\hline & Male & & & 90 & 42.3 \\
\hline & Female & & & 122 & 57.3 \\
\hline \multicolumn{6}{|l|}{ Ethnicity } \\
\hline & White/Caucasian/Non-Hispanic Origin & & & 96 & 45.1 \\
\hline & Asian/Asian American & & & 74 & 34.7 \\
\hline & Hispanic/Latino & & & 27 & 12.7 \\
\hline & Black/African American & & & 2 & 1.0 \\
\hline & Other & & & 14 & 6.5 \\
\hline \multicolumn{6}{|l|}{ Annual Salary } \\
\hline & $<\$ 20,000$ & & & 88 & 41.3 \\
\hline & $\$ 20,001-\$ 40,000$ & & & 59 & 27.7 \\
\hline & $\$ 40,001-\$ 60,000$ & & & 35 & 16.4 \\
\hline & $\$ 60,001-\$ 80,000$ & & & 13 & 6.1 \\
\hline & $\$ 80,001-\$ 100,000$ & & & 7 & 3.3 \\
\hline & $\$ 100,001-\$ 120,000$ & & & 3 & 1.4 \\
\hline & $\$ 120,001+$ & & & 3 & 1.4 \\
\hline
\end{tabular}

\section{Procedure}

Data were collected using both paper-and-pencil surveys and an online survey.

The online survey was posted on professional social networking websites (e.g., LinkedIn $\left({ }^{\circledR}\right)$ and on various professional forums prompting voluntary participants to participate in the survey measuring their perceptions of the workplace. Participants were also recruited from students in San José State University psychology and business courses. Participants were in a classroom and the researcher provided them with a brief explanation of the study, the consent form, and finally, the survey. Participants completed the paper-and-pencil survey and the researcher collected the completed surveys. 
All participants were informed of what the survey was intended to measure and were explicitly informed that their participation was completely voluntary, their data would be kept completely anonymous and confidential, and that they had the right to withdraw from the study at anytime. After informed consent, surveys were distributed and participants then responded to the survey consisting of three scales that measured participants' job embeddedness, work engagement, and demographic information.

\section{Measures}

Job embeddedness. Job embeddedness was measured using Mitchell et al.'s (2001) Job Embeddedness Scale, which consists of 40 items measuring six dimensions of job embeddedness. This included the dimensions of organizational links ( 7 items, $\alpha=$ .68 ), organizational fit (9 items, $\alpha=.88$ ), organizational sacrifice (10 items, $\alpha=.89$ ), community links (6 items, $\alpha=.52$ ), community fit (5 items, $\alpha=.78$ ), and community sacrifice (3 items, $\alpha=.57$ ).

Organizational and community links were measured with fill-in type items, asking participants questions regarding their links on- and off-the-job including items such as how long participants have worked for their organization, how many coworkers were highly dependent on them, whether or not they owned their own home, and whether or not they were married. Responses for each item were standardized and then averaged to create standardized composite scores for each dimension. Higher standardized composite scores represented greater levels of organizational and community links.

For the fit and sacrifice dimensions, items were measured on a 7-point Likert-type scale ranging from 1 (strongly disagree) to 7 (strongly agree). An example of an 
organizational fit item is "My coworkers are similar to me." An example of an organizational sacrifice item is "The perks on this job are outstanding." An example of a community fit item is "I really love the place where I live." An example of a community sacrifice item is "Leaving this community would be very hard." For each of the dimensions, responses were summed and then averaged. The range of scores for each dimension was between 1.0 and 7.0, with higher scores representing greater levels of organizational and community fit or sacrifice.

Work engagement. Work engagement was measured using Schaufeli and Bakker's (2003) UWES-17 Work Engagement Scale, which includes the three dimensions of absorption ( 6 items, $\alpha=.79$ ), dedication (5 items, $\alpha=.88$ ), and vigor (6 items, $\alpha=.80$ ). Items were measured on a 7-point Likert-type scale ranging from 1 (strongly disagree) to 7 (strongly agree). An example of an absorption item is "Time flies when I'm working." An example of a dedication item is "I find the work that I do full of meaning and purpose." An example of a vigor item is "At my work, I feel bursting with energy." For each work engagement dimension, responses were summed and averaged. The range of scores for the three dimensions was between 1.0 and 7.0, with higher scores representing higher levels of each dimension.

Demographics. Demographics were measured with four items: age, sex, ethnicity, and annual salary. 


\section{Descriptive Statistics}

\section{Results}

Table 2 displays the means and standard deviations, and intercorrelations among the measured variables. Among the predictor variables, organizational links $(M=.01, S D$ $=.65)$ and community links $(M=-.02, S D=.52)$ were standardized before creating composite subscore means. Thus, the means for links to organization and links to community were not directly comparable with the means for the fit and sacrifice dimensions of job embeddedness. Participants reported a moderate level of organizational fit $(M=4.65, S D=1.20)$ and organizational sacrifice $(M=4.15, S D=$ 1.29). For the same dimensions on the community aspects of embeddedness, participants reported high levels of community fit $(M=5.01, S D=1.14)$ as well as high levels of community sacrifice $(M=4.82, S D=1.15)$. Overall, for both the organization and community, participants perceived a high level of fit. Furthermore, participants reported a high degree of perceived sacrifice if they were to leave their organizations and communities.

With regard to the criterion variable of work engagement and its sub-dimensions, participants reported moderately high levels of overall work engagement $(M=4.64, S D=$ 1.09). For the three sub-dimensions of work engagement, absorption $(M=4.51, S D=$ $1.09)$, dedication $(M=4.67, S D=1.41)$, and vigor $(M=4.75, S D=1.05)$ were all reported at moderately high levels. Overall, participants were engaged in their jobs, with a higher level of vigor and dedication, followed by absorption. 
Of note, the three composite dimensions of both organizational and community embeddedness all showed moderate to high inter-correlations among each other, especially between community fit and community sacrifice $(r=.71)$, and between organizational fit and organizational sacrifice $(r=.78)$.

\section{Test of Hypotheses}

Pearson correlations were used to test the hypotheses that each of the three organizational embeddedness dimensions would be positively related to work engagement. Specifically, Hypothesis 1 stated that the number of perceived organizational links would be positively related to work engagement. In line with Hypothesis 1, perceived organizational links was significantly and weakly positively related to work engagement $(r=.14, p=.04)$. This result indicates that those who had many social and organizational ties at work were more likely to report that they were engaged in their work.

Hypothesis 2 stated that a perception of organizational fit would be positively related to work engagement. Consistent with Hypothesis 2, results showed that perceptions of organizational fit had a significant and positive correlation with work engagement $(r=.65, p<.001)$. The more participants perceived a fit within their organization, the more they were engaged with their work.

Hypothesis 3 predicted that a perception of organizational sacrifice would be positively related to work engagement. Results of the Pearson correlation showed that perceptions of organizational sacrifice were positively and significantly related to reports of work engagement $(r=.61, p<.001)$. The more participants perceived a sense of 
sacrifice if they were to leave their organizations, the more engaged they were with their work. Thus, Hypothesis 3 was supported. 
Table 2

Means, Standard Deviations, Pearson Correlations, and Alphas $(N=213)$

\begin{tabular}{|c|c|c|c|c|c|c|c|c|c|c|c|c|}
\hline Measure & Mean & SD & OL & $\mathrm{OF}$ & OS & CL & $\mathrm{CF}$ & $\mathrm{CS}$ & WE & $\mathrm{Ab}$ & De & $\mathrm{Vi}$ \\
\hline Organizational Links $^{\mathrm{a}}(\mathrm{OL})$ & .01 & .65 & $(.68)$ & & & & & & & & & \\
\hline Organizational Fit (OF) & 4.65 & 1.20 & .12 & $(.88)$ & & & & & & & & \\
\hline Organizational Sacrifice (OS) & 4.15 & 1.29 & $.23 * *$ & $.78 * * *$ & $(.89)$ & & & & & & & \\
\hline Community Links ${ }^{\mathrm{a}}$ (CL) & -.02 & .52 & $.28 * * *$ & .11 & .08 & $(.52)$ & & & & & & \\
\hline Community Fit (CF) & 5.01 & 1.14 & .06 & $.35 * * *$ & $.31 * * *$ & $.25 * *$ & $(.78)$ & & & & & \\
\hline Community Sacrifice (CS) & 4.82 & 1.15 & .07 & $.41 * * *$ & $.34 * * *$ & $.19 * *$ & $.71 * * *$ & $(.57)$ & & & & \\
\hline Work Engagement (WE) & 4.64 & 1.09 & $.14^{*}$ & $.65 * * *$ & $.61 * * *$ & .04 & $.15^{*}$ & $.29 * * *$ & $(.93)$ & & & \\
\hline Absorption (Ab) & 4.51 & 1.09 & $.17 *$ & $.54 * * *$ & $.53 * * *$ & .03 & .09 & $.24 * * *$ & $.91 * * *$ & $(.79)$ & & \\
\hline Dedication (De) & 4.67 & 1.41 & .11 & $.68 * * *$ & $.61 * * *$ & .03 & $.16^{*}$ & $.29 * * *$ & $.94 * * *$ & $.77 * * *$ & $(.88)$ & \\
\hline Vigor (Vi) & 4.75 & 1.05 & .12 & $.59 * * *$ & $.56 * * *$ & .08 & $.17^{*}$ & $.29 * * *$ & $.94 * * *$ & $.78 * * *$ & $.84 * * *$ & $(.80)$ \\
\hline
\end{tabular}

Note: $* p<.05, * * p<.01, * * * p<.001$

${ }^{a}$ Subscales were standardized

Reliability coefficients (alpha) presented on the diagonal 
These results showed that all of the organizational dimensions of job embeddedness were significantly and positively related to work engagement. Organizational fit $(r=.65)$ and organizational sacrifice $(r=.61)$ were both found to have the strongest and near equal correlations with work engagement, followed by organizational links $(r=.14)$.

The purpose of Research Questions 1a, 1b, and 1c was to discover and understand the relationships between non-work aspects of a person's life-space and work engagement. Pearson correlations were used for each of the three community embeddedness dimensions to uncover the little investigated relationships between community embeddedness and work engagement.

Research Question 1a asked "Is a perception of community links related to work engagement?" Results showed that community links had no significant relationship with work engagement $(r=.04, p=.55)$. Thus, the answer to Research Question 1a is that there was no relationship between community links and work engagement.

Research Question 1b asked, "Is a perception of community fit related to work engagement?" Results showed that community fit had a significant and positive relationship with work engagement $(r=.15, p=.03)$. This finding indicated as a person perceived more degree of fit in their community, he or she was more likely to be engaged at work. Thus, the answer to Research Question $1 \mathrm{~b}$ is that there was indeed a positive relationship between community fit and work engagement, though this relationship was somewhat weak. 
Research Question 1c asked "Is a perception of community sacrifice related to work engagement?" Results of the Pearson correlation showed that there was indeed a positive and significant relationship between a perception of community sacrifice and work engagement $(r=.29, p<.001)$. That is, the more a person believed that his or her community was worth preserving (i.e., a high degree of perceived sacrifice to leave), he or she was more likely to be engaged at work.

Of note, although Pearson correlations for two of the organizational embeddedness dimensions (fit, sacrifice) and two of the community embeddedness dimensions (fit, sacrifice) showed statistically significant relationships with work engagement, it should be understood that the magnitude of these relationships were two fold greater with the organizational embeddedness dimensions $(r=.65$ for organizational fit and $r=.61$ for organizational sacrifice) than the community embeddedness dimensions ( $r=.29$ for community sacrifice and $r=.15$ for community fit). These results indicated that although non-job dimensions of job embeddedness were related to work engagement, the organizational dimensions of job embeddedness were more important for the prediction of work engagement than the community dimensions of job embeddedness.

\section{Exploratory Analyses}

Going beyond simple correlation analyses to test the hypotheses, one of the important aspects of this study was to examine the relative importance of each dimension of job embeddedness in predicting work engagement. To investigate each dimension's unique relationship with work engagement, a standard multiple regression analysis was 
conducted in which all six dimensions of job embeddedness were entered into a multiple regression equation concurrently. A standard multiple regression analysis was conducted because the set of predictors were highly interrelated and there were no theoretical reasons to exclude any predictor variables.

Table 3 shows the results of multiple regression analysis. Results showed an overall significant relationship between the set of the predictor variables and the criterion, $R^{2}=.47, F(6,205)=30.71, p<.001$. Results indicate that $47 \%$ of the variance in work engagement was explained by the six dimensions of job embeddedness. Beta weights were examined to assess each predictor's unique contribution toward the prediction of work engagement. With regard to the organizational embeddedness dimensions of links, fit, and sacrifice, organizational fit had the highest unique contribution to the prediction of work engagement $(\beta=.45, p<.001)$. Organizational sacrifice was next highest predictor variable toward the prediction of work engagement $(\beta=.26, p=.002)$.

Surprisingly, organizational links had no unique contribution to the work engagement ( $\beta$ $=.03, p=.59)$.

Table 3

Standard Multiple Regression Analysis - Work Engagement

\begin{tabular}{lllll}
\hline & & $r$ & $\beta$ & $R^{2}$ \\
\hline Job Embeddedness & & & & $.47^{* * *}$ \\
& Organizational Links & $.14^{*}$ & .03 & \\
& Organizational Fit & $.65^{* * *}$ & $.45^{* * *}$ & \\
& Organizational Sacrifice & $.61^{* * *}$ & $.26^{* *}$ & \\
Community Links & .04 & -.02 & \\
& Community Fit & $.15^{*}$ & $-.20^{* *}$ & \\
Community Sacrifice & $.29^{* * *}$ & $.16^{*}$ & \\
\hline
\end{tabular}

Note: $* p<.05, * * p<.01, * * * p<.001$ 
Regarding the community embeddedness dimensions, perceived community fit had a significant unique contribution to the prediction of work engagement $(\beta=-.20, p=$ .008). This result indicated that the more fit one perceived in his or her community, the less he or she was engaged at work, controlling for the other variables. However, this result should be interpreted with caution - examination of the Pearson correlations between community fit and work engagement showed a significant and positive correlation $(r=.15, p=.03)$. Yet, results from the standard multiple regression analysis showed a relationship between the same two variables as a negative correlation. This result will be further clarified in the Discussion section.

For the dimension of community sacrifice, examination of beta coefficients revealed that this predictor variable provided significant and unique contribution to the prediction of work engagement $(\beta=.16, p=.03)$. As for the dimension of community links, beta coefficients were not significant $(\beta=-.02, p=.72)$. Thus, at least with regard to community sacrifice, results here suggested that aspects of community embeddedness may predict work engagement. Results showed that community fit and community sacrifice both provided significant and unique contribution to the prediction of work engagement, even when the presence of on-the-job embeddedness was controlled for.

This study aimed to identify unique relationships between the constructs of job embeddedness and work engagement that have not been examined previously. Thus, in essence, much of this study was exploratory in nature. Continuing with this theme, a canonical correlation analysis was conducted to explore, examine, and describe the overall relationship between the two sets of variables. The canonical correlation explains 
the relationship between the two sets of variables by determining the best linear combination between the first set of variables that show the largest correlation with the other set of variables (Hotelling, 1936).

Results of the canonical correlation analysis are shown in Table 4 and showed that the six dimensions of job embeddedness and the three dimensions of work engagement were significantly related to each other $(\lambda=.47, F(18,575)=9.80, p<.001)$. More than seventeen percent $(17.1 \%)$ of the variance in the work engagement variables was accounted for by the set of job embeddedness variables. Conversely, $41.4 \%$ of the variance in the set of job embeddedness variables was accounted for by the set of work engagement variables. This finding suggested that work engagement does a better job at predicting job embeddedness than job embeddedness does in predicting work engagement.

Table 4

Canonical Correlations - Job Embeddedness and Work Engagement

\begin{tabular}{llcc}
\hline Variable & & \multicolumn{2}{c}{ Function 1 } \\
\hline \multirow{5}{*}{ Predictor } & & Standardized & Structure \\
& & & \\
& Organizational Links & .03 & .17 \\
& Organizational Fit & .71 & .96 \\
& Organizational Sacrifice & .33 & .88 \\
& Community Links & -.07 & .02 \\
& Community Fit & -.26 & .22 \\
& Community Sacrifice & .20 & .41 \\
Criterion & & .15 & .83 \\
& Absorption & .83 & .99 \\
& Dedication & .05 & .87 \\
\hline
\end{tabular}


In canonical correlation, the linear combinations of variables that have the largest correlation with the second set of variables are called "roots." Each root generated however, is uncorrelated with the root that was produced before it. In the analysis, three roots were generated - however, only one root was found to explain significant variance between the two sets of variables. Standardized and structure coefficients from each function were checked to determine which variables showed unique and individual contribution to the significant relationships between variables. As a specification for cutoff values, .40 was used as a cutoff to differentiate between high and low correlations.

The first root accounted for $94.30 \%$ of the total variance in the sets of variables (canonical correlation $=.50$ ). Regarding the six dimensions of job embeddedness, organizational fit was the only variable that resulted in high standardized and high structure coefficients $(.71, .96)$. As for the set of criterion variables within the first root, dedication was the only variable resulted in a high standardized and high structure coefficient $(.83, .99)$. As a result, only organizational fit and dedication had the greatest significant and unique relation to each other, which suggested that as perceptions of organizational fit increase, so does the likelihood of an individual's dedication to their work. 


\section{Discussion}

Although the construct of job embeddedness has been used to explain voluntary turnover, research on job embeddedness has recently been expanded to investigate the relationships with various organizational constructs such as organizational citizenship behavior and innovation-related behaviors (Lee et al., 2004; Ng \& Feldman, 2010). The purpose of this study was to add to the existing literature on job embeddedness by exploring its relationship with work engagement. To date, this particular relationship has not received empirical investigation and understanding this relationship may provide unique insight into the specific dynamics between job embeddedness and work engagement. Additionally, this study went a step further by not only testing hypothesized relationships between job embeddedness and work engagement, but also by comparing the six dimensions of job embeddedness in terms of their unique ability to predict work engagement in a standard multiple regression analysis. Finally, this study went one more step further by investigating the relationship between the subdimensions of job embeddedness and work engagement. That is, the six dimensions that make up job embeddedness and three dimensions of work engagement were analyzed in a canonical correlation to examine which dimensions of job embeddedness have the largest linear combination with the dimensions of work engagement.

Hypotheses 1, 2, and 3 predicted that each of the three dimensions (i.e., links, fit, and sacrifice) of on-the-job embeddedness would be related to work engagement. In support of these hypotheses, it was found that each of these dimensions was significantly related to work engagement, and the nature of the relationship was in the predicted 
direction. Organizational fit and organizational sacrifice exhibited near equal and strong correlations with work engagement, followed by the weaker relationship of organizational links. It was argued that on-the-job embeddedness acted as job resources such as ties to those in one's organization (e.g., supervisor support), congruence with one's personal values and the values of the organization, and the reluctance to give up acquired job resources such as one's position in his or her company or valued relationships with familiar coworkers (Baker, Demerouti, \& Euwema, 2005; Chatman, 1989; Kristof, 1996). Because of the nature of the research design (i.e., correlational), we cannot infer causation that embedded workforces cause engaged workforces. Nonetheless, given the consistent relationship between job resources and work engagement (e.g., Bakker, Hakanen, Demerouti, \& Xanthopoulou, 2007; Mauno, Kinnunen, \& Ruokolainen, 2007), it is no surprise that job embeddedness is also related to work engagement.

The second major aspect of this study was to assess the relationship between community embeddedness and work engagement. In the past, very little attention has been given to literature regarding non-work aspects of a person's life-space with regard to work engagement. In this study, general research questions were presented for each of the three dimensions of community embeddedness in order to understand if these three dimensions were actually related to work engagement. Further, if there was indeed a relationship between community embeddedness and work engagement, what was the nature and direction of this relationship? 
From the results of the study, empirical support was found for two out of the three community embeddedness dimensions' relationship with work engagement. Community fit and community sacrifice were both found to have significant and positive relationships with work engagement. The correlation between community sacrifice and work engagement was nearly twice the correlation between community fit and work engagement. Thus, though both salient to the prediction of work engagement, community sacrifice plays a far more important role in explaining engagement than does community fit. This is the first evidence that supports the idea that non-work aspects of a person's "life-space" may be associated with work engagement. Last, community links was found to have no relationship with work engagement. As to why there is a relationship between community fit and community sacrifice with work engagement, interpretation of results should proceed with caution as it is unclear exactly what underlying psychological mechanisms are playing a role in this relationship.

However, one possible explanation for the relationships falls in line with the explanation by Lee et al. (2004) who argue that employees who value and want to stay in their communities that they live in are likely to view their community as a resource worth keeping. Following Hobfoll's (1989) conservation of resources theory which states that people are motivated to obtain and protect resources they personally value, people who perceive fit and do not want to leave their communities (i.e., they value the community in which they live) should be motivated to invest personal resources in order to keep the resources they already have - in this case, the community they live in. Because engagement is related to job performance, and because one's job performance is directly 
tied to maintaining one's job and or rank within an organization, it should follow that if individuals value their community, they would be more compelled to invest psychological, emotional, and physical resources into their job in order to maintain a satisfactory level of job performance in order to keep the job they are in.

A secondary purpose of this study was exploratory in nature and was conducted to have a deeper understanding regarding which job embeddedness dimensions predict work engagement the most while in the presence of the other predictor variables. To assess this, a multiple regression analysis was conducted to understand how the set of job embeddedness dimensions predicted work engagement as a single variable. Further, the decision was made to break the criterion variable of work engagement into its component dimensions of vigor, dedication, and absorption and conducted a canonical correlation analysis to understand which set of variables accounted for the largest amount of variance in the other set of variables.

Results of the multiple regression analysis revealed that four of the six dimensions of job embeddedness made significant and unique contribution for the prediction of work engagement. Going by their standardized beta weights, organizational fit accounted for the highest amount of unique variance in work engagement, followed by organizational sacrifice, community fit, and finally community sacrifice.

Results regarding organizational fit support the idea that congruence between one's own values and the values of his or her organization are tied to an increase in the investment of one's physical, psychological, and emotional resources on the job. With these increases of personal resources being invested in one's work, there lies a higher 
likelihood of work engagement (Chatman, 1989; Kristof, 1996). These results also fall in line with Maslach and Leiter's (1997) work engagement model, which argued that person-job congruity (which is similar in conceptualization as the job embeddedness dimension of organizational fit) is related to engagement with one's job. The results of this study add to the literature that shows that the most engaged employees are those who closely match the knowledge, skills, and abilities of the job they are in, even with the statistical predictive abilities of the other job embeddedness dimensions in the regression model.

Results pertaining to organizational sacrifice show that a perception of organizational sacrifice accounted for unique and significant variance in work engagement. This, again, supports Hobfoll's (1989) conservation of resources theory that states individuals are motivated to invest personal resources to protect valued resources, such as important and prized aspects of one's job.

As for the community embeddedness dimensions of fit and sacrifice, an interesting finding was that despite the presence of the dimensions of organizational embeddedness - especially with regard to organizational links - community fit and community sacrifice both predicted work engagement better than did organizational links. This finding is surprising, because the data suggest that a fit within one's community and perceived sacrifice to leave one's community has more predicative contribution to work engagement than does the number of formal and informal connections one has to their coworkers and organization. 
As a side note regarding community fit's positive Pearson correlation and negative standardized beta weight, the results, taken literally, suggest that when considered with community fit alone, community fit has a positive relationship with work engagement. However, taking into account the other dimensions of job embeddedness, increased community fit actually lowered one's engagement. This suggests that if one considers all dimensions excluding community fit, work engagement should be high. However, as community fit is considered in this equation, it explains significant unexplained variance in work engagement, and this explained variance actually translates to a lower predicted work engagement score in the regression model. This phenomenon is called "negative net suppression" - coined by Krus and Wilkinson (1986). In this situation, a variable can have a positive direct relationship with a dependent variable (i.e., positive Pearson correlation); however, its beta weight becomes negative in the presence of other variables (Krus \& Wilkinson, 1986).

The findings of the multiple regression may be explained by the possibility that community fit and community sacrifice represent a more encompassing view of one's happiness and contentment with their life-space and off-the-job surroundings, which may in turn, explain how individuals become engaged in their jobs. Additionally, the conceptualization of organizational links does not include a measure of the extent to which these links are important to them. Mitchell et al. (2001) acknowledges this limitation in their original conceptualization of their links definition: "We recognize that certain links may be more important than others and that these differences may be population-specific" (p. 1104). Therefore, it cannot be said with certainty that an 
individual with a high number of organizational links to those on the job actually places much value on these links. If a person has numerous links to an organization, but these social ties do not matter much to the individual, he or she might not view these links as important job resources that support one's ability to become engaged on the job.

The results regarding the canonical correlation analysis suggest that the two most related variables from both job embeddedness and work engagement are a perception of organizational fit and dedication to one's work. Of the six dimensions of job embeddedness and three dimensions of work engagement, these were the only two variables that exhibited high structure and standardized coefficients with regard to one another. This indicates that the two most important variables that explain the relationship between job embeddedness and work engagement are a high level of organizational fit, and a high level of dedication to one's work.

\section{Implications of the Current Study}

The purpose of this study was to find empirical support for the idea that job embeddedness is related to work engagement. Job embeddedness has only been introduced as a construct to predict turnover in the field of organizational psychology within the past twelve years (Mitchell et al., 2001), yet research on job embeddedness has already found to predict other employee behaviors such as OCB, and innovation-related behaviors (Lee et al., 2004; Ng \& Feldman, 2010). The results found in the current study add to the utility of job embeddedness as a predictor of additional employee behaviors; in this case, the likelihood of work engagement. Further, the individual dimensions that comprise job embeddedness were run in a multiple regression analysis to see how each 
dimension provided value toward the prediction of work engagement in order to better understand the unique contributions each dimension had with work engagement. While support was found for two of the three organizational embeddedness dimensions' relationship with work engagement (i.e., organizational fit and sacrifice), support was also found for the idea that non work-related aspects of a person's life-space (i.e., community fit and sacrifice) significantly predict work engagement. As a result, organizations seeking to increase work engagement may want to consider techniques that increase organizational embeddedness as well as community embeddedness.

Though human resource professionals and scholars have preached this for decades, the results of this study add to the evidence that companies interested in increasing work engagement need to increase their efforts toward hiring candidates who best fit with the culture of the company and the KSAs necessary for the job. Also, organizations looking to increase engagement should create new and innovative ways of increasing the perceived sacrifice necessary for their employees to leave their company. As an example, this can be achieved by investing in a comprehensive benefits package that appeals to a greater percentage of an organization's workforce - thus, providing more reason for employees to stay with the company for the long haul. Finally, organizations should find ways to increase the number of organizational links to their coworkers. Organizations may be able to increase links by introducing new work teams, committees, and possibly even holding more company events where employees can socialize with coworkers they otherwise would not have the chance to talk to during a normal workday. 
Additionally, based on the results from the multiple regression analysis, support was found for the idea that these non-work aspects of an individual's life-space provide unique insight into what is related to work engagement. These findings provide evidence that in addition to job-related factors that predict work engagement, non-work related factors might predict the degree to which employees become engaged on their job. These findings imply that off-the-job factors such as perceived community fit and perceived community sacrifices could be one's personal resources for becoming engaged on the job. This makes sense, as an individual's off-the-job life may not necessarily directly impact his or her engagement-related behaviors at work, but instead boost or take away from personal resources one needs to become engaged. Drawing from Maslow's (1943) hierarchy of needs, which proposes that basic human needs must be met before one can pursue higher level needs such as self-actualization, this idea can be explained that a sense of community embeddedness may be tied in to a sense of basic personal needs being met such as feeling safe and "at home" with where you live. Once these fundamental needs are met, according to Maslow (1943), an individual can then fully pursue higher-level needs such as motivation and engagement at work.

Furthermore, it was found that the dimensions of organizational fit and sacrifice, plus the dimensions of community fit and sacrifice all provided unique insight into work engagement. The most interesting finding in this case is that the off-the-job perceptions of fit and sacrifice provided unique insight into what created work engagement. It is noted that the organizational embeddedness dimensions of fit and sacrifice provided a greater level of insight in work engagement. Thus, these findings add value to the 
literature on non-work aspects of a person's life-space that contribute to the prediction of work engagement.

Finally, the results of the canonical correlation analysis suggest that organizational fit and dedication are the two most related variables within job embeddedness and work engagement. This implies that organizations trying to maximize employees' dedication to their work need to recruit and select employees who are most compatible with the values, goals, and future plans of the organization. Though this is a practice that many organizations already use, the findings only add support to the argument that employees who perceive a congruence of fit between their values and goals with those of the organization, the greater the likelihood that they will be dedicated to the work they do.

\section{Strength and Limitations of the Current Study}

Job embeddedness research was originally introduced to explain why employees choose to stay, rather than leave organizations (Mitchell et al., 2001). One major goal and strength of this study was to extend the utility of job embeddedness theory and assess the relationship between job embeddedness and work engagement. Moreover, multiple regression and canonical correlation analyses were conducted to examine how the dimensions of each construct differentially would be related to each other.

Another strength of the study was that evidence was found that connects nonwork aspects of a person's life-space with engagement on the job. Research on off-thejob variables that predict on-the-job outcomes is growing, and researchers have begun to increasingly place value on non-work aspects of a person's life-space that may be related 
to job outcomes (e.g., Kinnunen et al., 2011; Sonnentag et al., 2008). Organizations should take notice of what research findings are suggesting if they seek to increase positive organizational behaviors such as work engagement. Thus, an important strength of this study is that it provides insight and direction for organizations who are looking for new and "out of the box" ideas to increase positive employee behaviors.

As with every study that has strengths, there are also limitations to the findings found in this study. A few subscales within the dimensions of job embeddedness reported Cronbach's alphas below the commonly accepted reliability of .70 cut-off score (Nunnally, 1978). Community sacrifice had an alpha of .57, community links had an alpha of .52, and organizational links had an alpha of .68. Although the original measure of job embeddedness was validated and reported Cronbach's alphas of greater than .70, the Cronbach's alphas obtained in this study were a function of the sample collected thus, the researcher could not control the inter-item reliability. Given the relatively low reliabilities of these scales, findings pertaining to community sacrifice, organizational links, and community links should be interpreted with caution.

Another limitation of this study is the methodology behind the measurement of the link-related dimensions. The original job embeddedness scale (the one used in this study) measures the fit- and sacrifice-related dimensions using a 7-point Likert-type scale. However, measurement of the links-related dimensions is measured in a "fill in the blank" scale type. Thus, participants who answer items that ask about the number of links they have on- or off-the-job, have the possibility to answer between zero and anything beyond zero - leaving the likely opportunity for widely-varying responses from 
participants. This is likely what caused the unusually low Cronbach's alpha results for the links-related dimensions within job embeddedness - even after standardizing responses, because interpretation of the item and the resulting response was not limited to a specific range of answers. In contrast, the fit and sacrifice dimensions were measured using a limited range of responses (i.e., between one and seven) on the Likert-type scale, thereby leaving less opportunity for variance in the responses to items. In the future, measurement of the links-related items may need to be measured within a 7-point Likerttype scale, allowing for more controlled and limited set of responses for each item.

Another limitation of this study is the methodology used for recruiting participants. Because this study collected data from San José State University students and participants from social networking sites, participants who were not San José State University students and those who are not active on social networking websites were excluded. This methodology resulted in a primarily younger sample, often making under $\$ 20,000$ per year in salary. It also resulted in having participants who were often less progressed into their careers, because many participants were in entry-level positions within their organizations. A more accurate representation of the relationships between job embeddedness and work engagement may have been found if the sample consisted of a more diverse age group, salary range, and organizational levels.

\section{Directions for Future Research}

Future research needs to address the measurement of the links-related dimensions within job embeddedness. A more consistent measurement should be used throughout all of the dimensions of job embeddedness as to keep a universal train-of-thought and a more 
structured response set for participants when taking this measure. The author suggests revising the links-related items into a Likert-type response scale and then re-wording the items so that they can be answered using a "strongly disagree" to "strongly agree" response set. For instance, instead of asking "How many coworkers are highly dependent on you?" a new item can measure the same concept by measuring a participant's agreement with the following statement: "At work, I have many coworkers that are highly dependent on me." The same logic may apply to the measurement of community links. For example, a participant could then agree or disagree to an item such as "I feel that I know many people where I live.” By changing the methodology behind the measurement of the links-related dimensions, results would likely be more reliable and valid when assessing one's links to their organization and community.

Future research could also examine if there are types of workers who are embedded and engaged, and what the organizational outcomes are of workforces that possess these attributes. Drawing from this, organizations may be able to identify which employees are engaged, yet not embedded, or embedded yet not engaged. It may be important for organizations to analyze and understand what "types" of employees make up their workforce, and what are the outcomes of the different types of workforce populations. It is possible that disengaged employees are embedded, leading to low turnover, yet lower performance outcomes, or vice-versa - non-embedded employees who are engaged, leaving the possibility that an organization may have good workers who could easily leave the organization if their talent is in high demand at other organizations. The possibilities are not yet fully understood, and future research should 
examine these possibilities to understand the interplay between job embeddedness and work engagement.

\section{Conclusion}

This study found that job embeddedness is related to work engagement and that the dimensions that create job embeddedness are differentially predictive of work engagement. The current study found that all of the organizational embeddedness dimensions predicted work engagement; however, organizational fit and sacrifice performed significantly better at predicting work engagement than organizational links. Additionally, support was found for the general research question: "Is community embeddedness related to work engagement?" This study adds to the growing literature that supports the notion that off-work aspects of a person's life-space are relevant to the likelihood of becoming engaged at work. It was also found that the two most related aspects of job embeddedness and work engagement were a perception of organizational fit and dedication to one's job. Thus, when considering these two concepts, it is important to understand that a person who has a high degree of organizational fit may have a propensity for being highly dedicated to the work one does. Thus, a main takeaway that organizations can use from the results of this study is that organizations that are looking for dedicated workers should invest additional resources in their recruiting departments to develop processes that identify, recruit, and select candidates who have the highest level of congruence between their own core values and goals, with the core values and goals of their organizations. 


\section{References}

Bakker, A. B., \& Demerouti, E. (2007). The job demands-resources model: State of the art. Journal of Managerial Psychology, 22, 309-328.

Bakker, A. B., Demerouti, E., \& Euwema, M. C. (2005). Job resources buffer the impact of job demands on burnout. Journal of Occupational Health Psychology, 10, 170180.

Bakker, A. B., Demerouti, E., \& Schaufeli, W. B. (2005). The crossover of burnout and work engagement among working couples. Human Relations, 58, 661-669.

Bakker, A., Hakanen, J., Demerouti, E., \& Xanthopoulou, D. (2007). Job resources boost work engagement, particularly when job demands are high. Journal of Educational Psychology, 99, 274-284.

Chatman, J. A. (1989). Improving interactional organizational research: A model of person-organization fit. Academy of Management Review, 14, 333-349.

Cho, Y., \& Ryu, J. (2009). Organizational citizenship behaviors in relation to job embeddedness, organizational identification, job performance, voluntary turnover intention in Korea. International Business \& Economics Research Journal, 8(7), 51-68.

Demerouti, E., Bakker, A. B., Nachreiner, F., \& Schaufeli, W. B. (2001). The job demands-resources model of burnout. Journal of Applied Psychology, 86, 499512.

Griffeth, R. W., Hom, P. W., \& Gaertner, S. (2000). A meta-analysis of antecedents and correlates of employee turnover: Update, moderator tests, and research implications for the millennium. Journal of Management, 26, 463-488.

Harter, J. K., Schmidt, F. L., \& Hayes, T. L. (2002). Business-unit-level relationship between employee satisfaction, employee engagement, and business outcomes: A meta-analysis. Journal of Applied Psychology, 87, 268-279.

Hobfoll, S. E. (1989). Conservation of resources: A new approach at conceptualizing stress. American Psychologist, 44, 513-524.

Hobfoll, S. E., \& Shirom, A. (2001). Conservation of resources theory: Applications to stress and management in the workplace. In R. T. Golembiewski (Ed.), Handbook of Organizational Behavior (pp. 57-81). New York: Dekker.

Hom, P. W., \& Griffeth, R.W., (1995). Employee Turnover. Cincinnati: South/Western. 
Hotelling, H. (1936). "Relations between two sets of variates". Biometrika 28, 321-377.

Kahn, W. A. (1990). Psychological conditions of personal engagement and disengagement at work. Academy of Management Journal, 33, 692-724.

Kahn, W. A. (1992). To be fully there: Psychological presence at work. Human Relations, 45, 321-349.

Kinnunen, U., Feldt, T., Siltaloppi, M., \& Sonnentag, S. (2011). Job demands-resources model in the context of recovery: Testing recovery experiences as mediators. European Journal of Work and Organizational Psychology, 20, 805832.

Kristof, A. L. (1996). Person-organization fit: An integrative review of its conceptualizations, measurements, and implications. Personnel Psychology, 49, $1-49$.

Krus, D.J. and Wilkinson, S.M. (1986). Demonstration of properties of a suppressor variable. Behavior Research Methods, Instruments, and Computers, 18, 21-24.

Lee, T. W., Mitchell, T. R., Sablynski, C. J., Burton, J. P., \& Holtom, B. C. (2004). The effects of job embeddedness on organizational citizenship, job performance, volitional absences, and voluntary turnover. Academy of Management Journal, $47,711-722$.

Lewin, K. (1951). Field theory in social science: Selected theoretical papers (edited by Dorwin Cartwright), 1951.

Locke, E. A. (1975). Personnel attitudes and motivation. Annual Review of Psychology, 26, 457-480.

Lucas, S. (2012, November 21). How much does it cost companies to lose employees? Retrieved from http://www.cbsnews.com/8301-505125_162-57552899/howmuch-does-it-cost-companies-to-lose-employees/

Maertz, C. P., \& Campion, M. A. (1998). 25 years of voluntary turnover research: A review and critique. In C. L. Cooper \& I. T. Robertson (Eds.), International review of industrial and organizational psychology, vol. 13: 49-81. New York: Wiley.

Maslach, C., \& Leiter, M. P. (1997). The truth about burnout. San Francisco: JosseyBass. 
Maslow, A.H. (1943). A theory of human motivation. Psychological Review, 50, 370396.

Mauno, S., Kinnunen, U., Makikangas, A., \& Feldt, T. (2010). Job demands and resources as antecedents of work engagement: A qualitative review and directions for future research. In S. L. Albrecht (Ed.), Employee Handbook of Employee Engagement: Perspectives, Issues, Research and Practice (pp. 111-128). Northampton, MA: Edward Elgar Publishing, Inc.

Mauno, S., Kinnunen, U., Ruokolainen, M. (2007). Job demands and resources as antecedents of work engagement: A longitudinal study. Journal of Vocational Behavior, 70, 149-171.

Mitchell, T. R., Holtom, B. C., Lee, T. W. (2001). Why people stay: Using job embeddedness to predict voluntary turnover. Academy of Management Journal, $44,1102-1121$.

Mobley, W. H. (1977). Intermediate linkages in the relationship between job satisfaction and employee turnover. Journal of Applied Psychology, 62, 237-240.

Ng, T. W. H., \& Feldman, D. C. (2010). The impact of job embeddedness on innovationrelated behaviors. Human Resource Management, 49, 1067-1087.

Nunnally, J. C. (1978). Psychometric theory (2nd ed.). New York: McGraw-Hill.

Podsakoff, P. M., Ahearne, M., \& MacKenzie, S. B. (1997). Organizational citizenship behavior and the quantity and quality of work group performance. Journal of Applied Psychology, 82, 262-270.

Porter, L. W., \& Steers, R. M. (1973). Organizational, work, and personal factors in employee turnover and absenteeism. Psychological Bulletin, 80, 151-176.

Schaufeli, W. B., \& Bakker, A. B. (2003). UWES-Utrecht work engagement scale: test manual. Unpublished Manuscript: Department of Psychology, Utrecht University.

Schaufeli, W. B., Salanova, M., Gonzalez-Roma, V., \& Bakker, A. B. (2002). The measurement of engagement and burnout: A two-sample confirmatory factor analytic approach. Journal of Happiness Studies, 3, 71-92.

Sonnentag, S., \& Fritz, C. (2007). The recovery experience questionnaire: Development and validation of a measure for assessing recuperation and unwinding from work. Journal of Occupational Health Psychology, 12, 204-221. 
Sonnentag, S., Mojza, E., Binnewies, C. \& Scholl, A. (2008). Being engaged at work and detached at home: A week-level study on work engagement, psychological detachment, and affect. Work \& Stress, 22, 257-276.

Staw, B. M. (1980). The consequences of turnover. Journal of Occupational Behavior, 1, 253-273.

Welbourne, T. M., Johnson, D. E., \& Erez, A. (1998). The role-based performance scale: Validity analysis of a theory-based measure. Academy of Management Journal, $41,540-555$. 


\section{Appendix}

Survey Items

Job embeddedness (Mitchell et al., 2001)

1. Community Fit

a. I really love the place where I live.

b. The weather where I live is suitable for me.

c. This community is a good match for me.

d. I think of the community where I live as home.

e. The area where I live offers the leisure activities that I like.

2. Organizational Fit

a. I like the members of my work group.

b. My coworkers are similar to me.

c. My job utilizes my skills and talents well.

d. I feel like I am a good match for this company.

e. I fit with the company's culture.

f. I like the authority and responsibility I have at this company.

g. My values are compatible with the organization's values.

h. I can reach my professional goals working for this organization.

i. I feel good about my professional growth and development.

3. Community Sacrifice

a. Leaving this community would be very hard.

b. People respect me a lot in my community.

c. My neighborhood is safe.

4. Organizational Sacrifice

a. I have a lot of freedom on this job to decide how to pursue my goals.

b. The perks on this job are outstanding.

c. I feel that people at work respect me a great deal.

d. I would sacrifice a lot if I left this job

e. My promotional opportunities are excellent here.

f. I am well compensated for my level of performance.

g. The benefits are good on this job.

h. The health-care benefits provided by this organization are excellent.

i. The retirement benefits provided by this organization are excellent.

j. The prospects for continuing employment with this company are excellent. 
5. Community Links

a. Are you currently married?

b. If you are married, does your spouse work outside the home?

c. Do you own the home you live in?

d. My family roots are in this community.

e. How many family members live nearby?

f. How many of your close friends live nearby?

6. Organizational Links

a. How long have you been in your present position?

b. How long have you worked for this company?

c. How long have you worked in this industry?

d. How many coworkers do you interact with regularly?

e. How many coworkers are highly dependent on you?

f. How many work teams are you on?

g. How many work committees are you on?

\section{UWES-17 Work Engagement Scale}

1. Absorption

a. Time flies when I'm working.

b. When I am working, I forget everything else around me.

c. I feel happy when I am working intensely.

d. I am immersed in my work.

e. I get carried away when I'm working.

f. It is difficult to detach myself from my job.

2. Dedication

a. I find the work that I do full of meaning and purpose.

b. I am enthusiastic about my job

c. My job inspires me.

d. I am proud on the work that I do.

e. To me, my job is challenging.

3. Vigor

a. At my work, I feel bursting with energy.

b. At my job, I feel strong and vigorous.

c. When I get up in the morning, I feel like going to work.

d. I can continue working for very long periods at a time.

e. At my job, I am very resilient, mentally.

f. At my work I always persevere, even when things do not go well. 


\section{Demographics}

1. What is your age?

2. What is your sex?
a. $\square$ Male
b. $\square$ Female

3. What is your ethnicity?
a. $\square$ White/Caucasian
b. $\square$ Hispanic/Latino
c. $\square$ Black/African-American
d. $\square$ Asian/Asian-American
e. $\square$ Other (please specify)

4. Annual Salary
a. $\square \$ 20,000$ or less
b. $\square \$ 20,001$ to $\$ 40,000$
c. $\square \$ 40,001$ to $\$ 60,000$
d. $\square \$ 60,001$ to $\$ 80,000$
e. $\square \$ 80,001$ to $\$ 100,000$
f. $\square \$ 100,001$ to $\$ 120,000$
g. $\square \quad \$ 120,001$ and above 